\title{
Evaluation of Factors Affecting Perioperative Mortality in Newborns with Critical Congenital Heart Disease
}

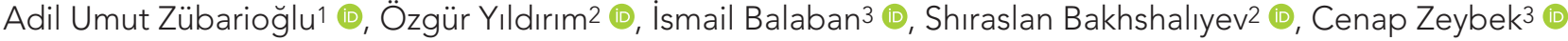 \\ ${ }^{1}$ İstanbul Yeni Yüzyıl University Faculty of Medicine, Department of Neonatology, İstanbul, Turkey \\ ${ }^{2}$ ístanbul Yeni Yüzyıl University Faculty of Medicine, Department of Pediatric Cardiovascular Surgery, İstanbul, Turkey \\ ${ }^{3}$ İstanbul Yeni Yüzyıl University Faculty of Medicine, Department of Pediatric Cardiology, İstanbul, Turkey
}

Cite this article as: Zübarioğlu AU, Yıldırım Ö, Balaban I, Bakhshalıyev S, Cenap Zeybek C. Evaluation of Factors Affecting Perioperative Mortality in Newborns with Critical Congenital Heart Disease. JAREM 2020;10(1): 64-9

\begin{abstract}
Objective: Congenital heart diseases (CHD) are most common malformation group in neonatal period and their frequency ranges from 6 to 8 in 1.000 live births. Critical CHD constitutes approximately $25 \%$ of group and results in mortality if not diagnosed and treated in neonatal period. The aim of our study was to determine the factors affecting the perioperative mortality of patients with critical CHD.

Methods: Our study was performed retrospectively between July 2017 and December 2018. The demographic data, echocardiographic diagnosis and comorbidities of the patients were recorded. Patients who were discharged and who were dead were compared in terms of risk factors. In the descriptive analyses, the student's t-test was used for normally distributed numerical variables and the Mann-Whitney $U$ test was used for non-normally distributed variables. Categorical variables were presented in percentages and by using cross tables.

Results: Ninety-two cases were included in the study, 19 were premature and 16 had additional organ anomalies, 23.9\% had low birth weight. The rate of antenatal diagnosis was $39.1 \%$ and $14.1 \%$ of the cases needed resuscitation in the delivery room. During admission, 41 cases needed inotropic agent. Low birth weight, prematurity, resuscitation need, additional organ anomaly and need for inotropic support were found to be statistically significant in the mortality group $(p=0.027,0.026,0.001,0.001,0.022$, respectively).

Conclusion: Prematurity, low birth weight, and additional organ anomalies are critical risk factors for cardiac malformation. In addition, patients with active cardiopathy during intrauterine period are more resuscitated in the delivery room, their inotropic needs are higher, and they have higher mortality.

Keywords: Newborn, critical congenital heart disease, mortality
\end{abstract}

\section{INTRODUCTION}

Congenital heart disease (CHD) is the most common malformation group seen in the newborn period and its frequency varies between 6-8 per 1.000 live births (1). This group includes a range of diseases ranging from benign anomalies to severe anomalies in which early diagnosis and treatment are required for the baby to survive. The subgroup of severe anomalies is called critical CHD and its frequency is $1.2 / 1.000$ live births $(1,2)$. Unfortunately, these cases, which are associated with high mortality and morbidity in case of delay in diagnosis, may not give finding until the mother and baby couple are discharged (3).
With the increase in antenatal diagnosis opportunities and the spread of the CHD screening program with pulse oximetry in the postnatal period, the rates of diagnosis were increased before the newborn babies became symptomatic. Although it is a logical approach that a patient with critical CHD may have an antenatal diagnosis and proper perinatal management, its prognosis may be better, contradictory results have been obtained in the studies on the subject. Although some studies have found significant improvements in surgical survival in severe congenital heart anomalies such as hypoplastic left heart syndrome (HLHS), aortic coarctation, and large arterial transposition, other studies have not shown that being diagnosed with antenatal in similar patient 


\section{Data of Cases}

populations creates a significant advantage (4-8). The reason for this is that antenatal detection rates of anomalies with a much heavier and fatal single ventricle physiology are higher.

Critical CHD mortality in developed countries varies between 15 and $25 \%$ and varies according to the type of cardiac defect and time of diagnosis (9-11). Although the prognosis has improved due to the advances in medical and surgical methods, the risk of mortality and morbidity still continues compared to the normal population (12).

In the studies conducted, additional factors such as accompanying major organ anomalies, chromosomal disorders, low birth weight of the case, premature birth and low APGAR score as well as the severity of cardiac anomaly were found to contribute to the surgical mortality of these patients $(13,14)$. However, since these studies did not include cases who were lost before surgery or intervention or whose pathology was not suitable for intervention, they cannot fully demonstrate perioperative risk factors.

The aim of our study is to reveal the risk factors affecting the perioperative mortality of the newborns diagnosed with critical CHD and followed and treated in our center, which is a $3^{\text {rd }}$ level neonatal intensive care and congenital cardiac surgery clinic.

\section{METHODS}

Design: Our study was conducted as single-centered by retrospectively examining the files of the patients diagnosed with critical CHD, who were followed up in the neonatal intensive care unit of our hospital in a single-center period in the 18-month period between July 2017 and December 2018.

Definition: Critical CHD is a structural cardiac malformation that progresses with mortality and morbidity, causing cardiovascular insufficiency when not treated in the first 4 weeks of neonatal period. Large artery transposition (LAT), aortic coarctation, intermittent arcus aorta, critical aortic valve stenosis, HLHS, pulmonary atresia/ critical pulmonary valve stenosis, tricuspid atresia, Fallot tetralogy which is critical pulmonary outflow stenosis, and single ventricle cases, Ebstein anomaly, truncus arteriosus and total abnormal pulmonary venous return anomaly are included in this group.

\section{Inclusion Criteria}

In our study, patients who were referred to our neonatal intensive care unit during the neonatal period (first postnatal 28 days) for the pre-diagnosis of $\mathrm{CHD}$ and whose echocardiography revealed critical CHD were included.

\section{Exclusion Criteria}

1. Structural congenital malformations (ventricular septal defect, complete atrioventricular septal defect, atrial septal defect, and Fallot tetralogy cases with good pulmonary artery anatomy) that do not require intervention (angiography, cardiac surgery) but require medical follow-up in the neonatal period.

2. Cases of premature ductus arteriosus cases without a response to medical treatment, who were directed to us from external centers for surgical treatment, were not included in the study.
The centers the cases came from (external center, our hospital), gender, birth weight, gestational week, type of delivery, need for resuscitation in the delivery room (positive pressure ventilation, intubation, chest compression, drug administration), time of diagnosis (before antenatal, postpartum discharge of mother and baby at the hospital, application from the home postnatally), the day of admission to our hospital (for those admitted in the first 24 hours or for cases born in our hospital, the day of admission was recorded as the $1^{\text {st }}$ day), and mechanical ventilator support during the application to our center (non-invasive or invasive) and/ or receiving inotropic drugs, day of intervention (angiography, cardiac surgery), pre-intervention period, echocardiography diagnosis, other accompanying organ anomalies, discharge time, whether there was mortality before or after the intervention, if there was mortality, the time and cause were recorded in the prepared forms.

Independent variables were prematurity (gestational week $36+$ 6/7 and smaller), low birth weight (less than 2.500 grams), having an antenatal diagnosis, presence of other organ anomalies, need for resuscitation in the delivery room, need for a mechanical ventilator during admission to our center, and need for inotropic agent at admission.

Dependent variables were pre-intervention mortality and mortality during hospitalization.

\section{Ethics Committee Approval and Patient Consent}

Ethics committee approval of our study was obtained from the Ethics Committee for Science, Social and Non-Interventional Health Sciences Research at University of Health Sciences, İstanbul Yeni Yüzyıl University (approval number: 2019/2, date: 04.02.2019). Written consent was obtained from the families of all cases included in the study prior to medical and surgical interventions.

\section{Statistical Analysis}

Statistical analyses were performed using SPSS version 13 software. Descriptive analyses were given using the mean and standard deviations for normally distributed numerical variables and compared using the student's t-test. Non-normally distributed variables were given using median and interquartile values and compared using the Mann-Whitney $U$ test. Categorical variables were presented as a percentage and given using cross tables. Whether there was a difference between the groups was compared using the chi-square or Fisher tests. Situations in which the P-value was below 0.05 were considered statistically significant.

\section{RESULTS}

Of the 92 cases included in the study, 57 (62\%) were male and $19(20.6 \%)$ were preterm babies. The mean gestational week was $37.8 \pm 2.1$ weeks, and the mean birth weights were $2.986 \pm 680$ grams. The number of cases with low birth weight ( $<2.500$ grams) was $22(23.9 \%)$. While the rate of having a prenatal diagnosis was $39.1 \%, 14.1 \%$ of the study group needed resuscitation in the delivery room. 
The average day of admission of cases to our clinic was 4.7 days. During the application, 52 cases received mechanical ventilation (42 invasive, 10 non-invasive), and 41 received inotropic agent support. During the clinical follow-up, 6 cases died without any intervention, and 19 cases died during or after the intervention. While the overall mortality of the case group was $27 \%$, intervention mortality was $22 \%$. The demographic and clinical features of the cases are detailed in Table 1.

In 16 of the cases, there were other organ anomalies and genetic disorders accompanying cardiac anomalies. Trisomy 21, renal agenesis/hypoplasia, esophageal atresia were the most common anomaly and genetic disorder with two cases. Genetic and organ anomalies detected in the study group are given in detail in Table 2.

Cyanotic CHD was present in 72 (78.2\%) of the cases. According to the frequency of occurrence, 24 cases with HLHS, 18 cases with LAT, and 12 cases with pulmonary atresia were on the first three ranks. The diagnoses of our acyanotic cases were aortic coarctation and intermittent arcus aorta (20 cases in total). Distribution of the cases according to their echocardiographic diagnosis is shown in Table 3.

The majority of the cases lost during their clinical follow-up were followed up with the diagnosis of HLHS (2 before, 10 during and after the intervention). Mortality was observed in 9 cases with a rate of $14 \%$ in 64 cases who were diagnosed and attempted other than HLHS. The distribution of lost cases by diagnosis and time of mortality is shown in Table 4.

When the factors affecting the prognosis during clinical follow-up of the cases were examined, the rates of having low birth weight, being born prematurely, the need for resuscitation in the delivery room, other accompanying organ anomalies and the need for an inotropic agent at the time of admission to our clinic were found to be statistically significant in cases that resulted in mortality. Comparative analysis of the two groups is shown in Table 5.

\section{DISCUSSION}

$\mathrm{CHDs}$ are the most common major birth defect and mostly consist of mild lesions that do not require intervention (small ventricular septal defect, atrial septal defect, mild pulmonary stenosis). However, 1/3-1/4 of the cases are in the critical CHD group that requires early intervention. While children with severe CHD had a $30 \%$ chance of getting adult until fifty years ago, success was increased in interventional procedures and a serious improvement in prognosis was observed as a result of increased knowledge in cardiac surgery and cardiology and dizzying technological developments (14). Thanks to the developments in the field of obstetrics and neonatology, recognition of these cases in the fetal period, careful antenatal follow-up, appropriate management of the natal and postnatal period were provided and contributed to the improvement in prognosis.

The main factors that determine surgical mortality in critical CHD are the severity of cardiac malformation, the time of diagnosis and other accompanying features $(15,16)$. In our study, while our perioperative mortality rate was $27 \%$, our intervention mortality was $22 \%$ similar to the data of developed countries. We think that our perioperative and surgical mortality increased because of the patients with HLHS at the rate of $26.1 \%$ and high mortality of this diagnostic group globally. In the literature, neonatal mortality increases to as high as $68 \%$ in patients with HLHS (15). In our case

Table 1. Demographic and clinical features of cases included in the study

Gender, $n$ (\%)

Female

$35(38)$

Male

57 (62)

Birth weight (mean \pm standard deviation, minimum-maximum)

$2986.7 \pm 680.8$

(920-4810)

Gestational week (mean \pm standard deviation, minimum-maximum)

$37.8 \pm 2.1(29-41)$

Place of birth, $n$ (\%)

External center

85 (92.4)

Our hospital

7 (7.6)

\section{Type of delivery ${ }^{\mathrm{p}}, \mathrm{n}(\%)$}

Nsvd

45 (48.9)

Cs

$47(51.1)$

Delivery room resuscitation, $\mathrm{n}(\%)$

$13(14.1)$

Time of diagnosis ${ }^{\beta}, \mathbf{n}(\%)$

Antenatal

36 (39.1)

Postnatal hospital

30 (32.6)

Postnatal home

$26(28.3)$

Admission day (mean \pm standard deviation, minimum-maximum)

Mechanical ventilator support at admission, $n$ (\%)

$4.7 \pm 5.3(1-26)$

$52(56.5)$

Non-invasive, $\mathrm{n}$

Invasive, $\mathrm{n}$

Inotropic agent need at admission, $\mathrm{n}(\%) \quad 41$ (44.6)

Duration of pre-intervention hospitalization

(mean \pm standard deviation, minimummaximum)

Day of operation (mean \pm standard deviation, minimum-maximum)

Day of discharge (mean \pm standard deviation, minimum-maximum)

Mortality, n/total (\%)

Before intervention

$25 / 92(27 \%)$

$6 / 92(6.5 \%)$

Intervention and afterwards

$19 / 92(20.6 \%)$

Intervention mortality, $\mathrm{n} /$ total intervention (\%)

$19 / 86(22 \%)$

Mortality day (mean \pm standard deviation,

$26.7 \pm 27.1(2-119)$ minimum-maximum)

${ }^{p}$ Nsvd: Normal spontaneous vaginal delivery, Cs: caesarian delivery, ${ }^{B}$ Postnatal Hospital: diagnosis before the discharge of mother and baby, Postnatal home: diagnosis after the emergence of symptoms after motherbaby couple is discharged to home 
group, this rate was $50 \%$ perioperatively and $45 \%$ postoperatively. The overall mortality of our cases with other echocardiographic diagnoses was $19 \%$.

In our study, besides the severity of heart anomaly, other factors affecting mortality were found to be having low birth weight, preterm birth, need for resuscitation in the delivery room, accompanying other organ anomaly and need for inotropic agents during admission.

When the literature is examined, it was found that the low APGAR score $\left(5^{\text {th }}\right.$ minute score $\left.<7\right)$ in various studies increased surgical

\begin{tabular}{l|l|}
$\begin{array}{l}\text { Table 2. Other organ anomalies and genetic } \\
\text { accompanying heart anomaly }\end{array}$ & $\mathbf{1 6}$ (17.4) \\
\hline Accompanying anomalies, $\mathrm{n}$ (\%) & 2 \\
\hline Trisomy $21, \mathrm{n}$ & 2 \\
\hline Renal agenesis/hypoplasia, $\mathrm{n}$ & 2 \\
\hline Esophageal atresia, $\mathrm{n}$ & 1 \\
\hline Hydrocephalus, $\mathrm{n}$ & 1 \\
\hline Congenital cataract, $\mathrm{n}$ & 1 \\
\hline Corpus callosum agenesis, $\mathrm{n}$ & 1 \\
\hline Sacrococcygeal teratoma, $\mathrm{n}$ & 1 \\
\hline Posterior urethral valve, $\mathrm{n}$ & 1 \\
\hline Anal atresia, $\mathrm{n}$ & 1 \\
\hline Microcephaly, $\mathrm{n}$ & 1 \\
\hline Bronchomalacia, $\mathrm{n}$ & 1 \\
\hline Cleft palate, $\mathrm{n}$ & 1 \\
\hline Biliary atresia, $\mathrm{n}$ & \\
\hline $\mathrm{n}$ : Number & \\
\hline
\end{tabular}

\begin{tabular}{l|l|l|}
\hline $\begin{array}{l}\text { Table 3. Distribution of cases according to echocardiographic } \\
\text { diagnoses }\end{array}$ & $\begin{array}{l}\text { Number } \\
\text { of cases } \\
\text { (n) }\end{array}$ & $\begin{array}{l}\text { Ratio } \\
\text { to total } \\
\text { number of } \\
\text { cases (\%) }\end{array}$ \\
\hline Cyanotic congenital heart disease & $\mathbf{7 2}$ & $\mathbf{7 8 , 2}$ \\
\hline Hypoplastic left heart syndrome & 24 & 26,1 \\
\hline Great arterial transposition & 18 & 19,6 \\
\hline Pulmonary atresia & 12 & 13 \\
\hline Fallot tetralogy & 4 & 4,3 \\
\hline $\begin{array}{l}\text { Total abnormal pulmonary venous return } \\
\text { anomaly }\end{array}$ & 4 & 4,3 \\
\hline Tricuspid Atresia & 3 & 3,3 \\
\hline $\begin{array}{l}\text { Double outlet right ventricle + pulmonary } \\
\text { stenosis }\end{array}$ & 3 & 3,3 \\
\hline Critical pulmonary stenosis & 3 & 3,3 \\
\hline Ebstein anomaly & 1 & 1,1 \\
\hline Acyanotic congenital heart disease & $\mathbf{2 0}$ & $\mathbf{2 1 , 7}$ \\
\hline Aorta coarctation & 14 & 15,2 \\
\hline Intermittent arcus aorta & 6 & $\mathbf{6 , 5}$ \\
\hline Total & $\mathbf{9 2}$ & $\mathbf{1 0 0}$ \\
\hline
\end{tabular}

mortality (14). The reason for this was explained in the way that cardiopathy was active in the antenatal period and the supply of nutrients and oxygen to the fetus was insufficient.

In another study involving 439 newborns with an antenatal diagnosis rate of $67 \%$, the fact that the APGAR scores of the case did not correlate with the diagnosis time reinforces this hypothesis (7). In our study, the problem of adaptation to postnatal life, which is a different dimension of this situation, was observed, 13 cases (14.1\%) needed resuscitation in the delivery room. The fact that

\begin{tabular}{|c|c|c|c|}
\hline $\begin{array}{l}\text { Echocardiographic } \\
\text { Diagnosis }\end{array}$ & $\begin{array}{l}\text { Pre- } \\
\text { intervention } \\
\text { mortality }\end{array}$ & $\begin{array}{l}\text { During } \\
\text { and post } \\
\text { interventional } \\
\text { mortality }\end{array}$ & $\begin{array}{l}\text { Total mortality/ } \\
\text { total number of } \\
\text { cases, (\%) }\end{array}$ \\
\hline $\begin{array}{l}\text { Hypoplastic left } \\
\text { heart syndrome }\end{array}$ & 2 & 10 & $12 / 24(50 \%)$ \\
\hline $\begin{array}{l}\text { Great arterial } \\
\text { transposition }\end{array}$ & 2 & 2 & $4 / 18$ (22.2\%) \\
\hline Pulmonary atresia & - & 3 & $3 / 12$ (25\%) \\
\hline Aorta coarctation & - & 2 & 2/14 (14.2\%) \\
\hline $\begin{array}{l}\text { Double outlet } \\
\text { right ventricle } \\
+ \text { pulmonary } \\
\text { stenosis }\end{array}$ & - & 2 & $2 / 3(66.6 \%)$ \\
\hline $\begin{array}{l}\text { Intermittent arcus } \\
\text { aorta }\end{array}$ & 1 & - & $1 / 6(16.6 \%)$ \\
\hline Ebstein anomaly & 1 & - & $1 / 1(100 \%)$ \\
\hline Total & 6 & 19 & 25/92 (27.1\%) \\
\hline
\end{tabular}

Table 5. Evaluation of risk factors affecting mortality of cases

\begin{tabular}{|l|l|l|l|}
\hline Parameter & $\begin{array}{l}\text { Cases resulting } \\
\text { in discharge } \\
\text { (n=67) }\end{array}$ & $\begin{array}{l}\text { Cases } \\
\text { resulting in } \\
\text { mortality } \\
\text { (n=25) }\end{array}$ & p \\
\hline $\begin{array}{l}\text { Birth weight (mean } \pm \\
\text { standard deviation) }\end{array}$ & $3073.8 \pm 599.9$ & $2753.4 \pm 830.3$ & 0.087 \\
\hline $\begin{array}{l}\text { Low birth weight } \\
\text { (<2500 gram) }\end{array}$ & $12(17.9 \%)$ & $10(40 \%)$ & $\mathbf{0 . 0 2 7}$ \\
\hline $\begin{array}{l}\text { Gestational week } \\
\text { (mean } \pm \text { standard } \\
\text { deviation) }\end{array}$ & $38.3 \pm 1.6$ & $36.6 \pm 2.8$ & $\mathbf{0 . 0 0 7}$ \\
\hline $\begin{array}{l}\text { Premature birth (<37 } \\
\text { gestational week) }\end{array}$ & $10(14.9 \%)$ & $9(36 \%)$ & $\mathbf{0 . 0 2 6}$ \\
\hline $\begin{array}{l}\text { Absence of antenatal } \\
\text { diagnosis }\end{array}$ & $38(56.7 \%)$ & $18(72 \%)$ & 0.181 \\
\hline $\begin{array}{l}\text { Need for resuscitation } \\
\text { in the delivery room }\end{array}$ & $3(4.4 \%)$ & $10(40 \%)$ & $\mathbf{0 . 0 0 0}$ \\
\hline $\begin{array}{l}\text { Need for mechanical } \\
\text { ventilator at admission }\end{array}$ & $36(53.7 \%)$ & $16(64 \%)$ & 0.377 \\
\hline $\begin{array}{l}\text { Need for inotropic } \\
\text { agent at admission }\end{array}$ & $25(37.3 \%)$ & $16(64 \%)$ & $\mathbf{0 . 0 2 2}$ \\
\hline $\begin{array}{l}\text { Accompanying other } \\
\text { organ anomaly }\end{array}$ & $6(8.9 \%)$ & $10(40 \%)$ & $\mathbf{0 . 0 0 0}$ \\
\hline & & & \\
\hline
\end{tabular}


10 of the resuscitated cases resulted in mortality also showed that cardiopathy, which started in the antenatal period in congenital heart patients and affected postnatal adaptation, was closely related to surgical mortality. Again, in our study, we found that overall mortality was significantly higher in patients who needed inotropy to provide normotension and cardiac contractility before intervention due to this cardiopathic condition.

Studies have shown that low birth weight is an important factor in mortality in congenital cardiac surgery (17-19). In our study, although the birth weight average of the group that resulted in mortality was lower than the group discharged, this difference was not statistically significant $(p=0.087)$. However, the rate of the number of cases below 2.500 grams, which was accepted as the surgical margin in the majority of the studies, was found to be significantly higher in the group resulting in mortality. In addition to increasing the surgical risk, low birth weight increases mortality as an independent risk factor in the pre-intervention period. The low birth weight of 4 of our 6 cases who died before intervention reveals this risk.

Being born prematurely is the cause of low birth weight in addition to immature organ systems and plays an important risk factor for cardiac surgery. In the literature, it has been shown to be an important risk in many studies, and some studies have identified below 39 pregnancy weeks for surgical risk (19-21).

In accordance with the literature, our study found that the mean gestational week was significantly lower in the mortality group $(36.6 \pm 2.8$ gestational weeks versus $38.3 \pm 1.6)$, and the prematurity rate was as high as $36 \%$ to $14.9 \%$. Both parameters are statistically significant ( $p=0.007$ and 0.026 , respectively). The fact that $50 \%$ $(n=3)$ of the cases lost before intervention was preterm shows that being born before 37 weeks of gestation is an independent risk in terms of decreasing the chance of intervention.

It is known that the cause of $20 \%$ of CHD cases is a part of chromosome anomalies, single gene disorders and syndromes (22). In our study group, 14 (15.2\%) patients had accompanying non-cardiac anomalies, while $2(2.1 \%)$ cases had trisomy 21. Extracardiac anomalies and chromosomal disorders have been shown to increase the risk of mortality in critical CHDs (23). In our study, the frequency of non-cardiac anomalies was found to be significantly higher in the group with mortality. Again, 3 of the 6 cases lost before the intervention were found to have major organ anomalies.

Among the factors affecting the critical CHD prognosis, one of the most studied conditions is the timing of diagnosis. While prenatal diagnosis rates are around $30-40 \%$ especially in developed countries in the early 2.000 s, this rate has reached the $75-80 \%$ band in recent years $(6,24)$. In various studies, cases with antenatal diagnosis were compared with undiagnozed cases in terms of mortality. It is thought that having an antenatal diagnosis allows immediate start of medical treatment for the maintenance of the ductus patency of the newborn baby, thereby preventing metabolic acidosis, hypoxemia and end organ damage and reducing mortality and morbidity. In many case series, it has been shown to reduce the mortality rate in patients with HLHS, LAT, and aortic coarctation (4-6). However, these findings were not repeated in studies with similar case series and no difference was found in terms of mortality and postnatal diagnosis $(8,24)$. This has been attributed to increased frequency of diagnosis of more complex and severe cardiac anomalies such as HLHS with increasing frequency of fetal echocardiography. In the study of Oster et al. (15), early diagnosis and poor prognosis were found to be correlated. The reason for this situation is that the group with antenatal diagnosis has more complex cardiac anomalies, and fetal echocardiography is performed in patients with chromosome anomalies detected in screening tests. In our study, when patients with and without antenatal diagnosis were compared in terms of mortality, no significant effect on survival was shown. Although 18 of 25 cases resulting in mortality did not have antenatal diagnosis, 38 of our 67 cases did not have prenatal diagnosis. In our case group, we think that the most common echocardiographic diagnosis group is those with HLHS and the diagnosis timing does not change the prognosis because the severity of the disease determines surgical mortality in this anomaly. However, none of the 6 cases with mortality in the pre-intervention period had antenatal diagnosis, and this emphasizes the importance of this condition. As soon as the newborn is diagnosed, it is possible to make the necessary interventions in ideal conditions, as well as to prepare the family for the psychological condition and to have them get information about the disease of their babies (25). As a matter of fact, in a metanalysis including 8 studies, it has been found that antenatal diagnosis reduces mortality before planned surgery (10).

\section{CONCLUSION}

Being born prematurely, having low birth weight, and additional organ anomaly are risk factors independent of the severity of cardiac malformation in terms of mortality in critical CHD. Apart from these, the patients whose cardiopathies are active in the intrauterine period are more resuscitated in the delivery room, their inotropic needs are higher and progress with higher mortality. With the increase in antenatal diagnosis rates, the patients with this high risk can be given care under more favorable conditions and the mortality rate before the intervention will decrease. We also think that postoperative mortality will decrease as these cases can be intervened in a better clinical condition.

It will be possible to reach the rates in developed countries by combining perinatal centers with cardiac surgery centers for increasing their number and expanding them to all regions in our country, which will shorten the transport time, and by working in close cooperation with newborn clinics and child intensive care specialists in surgical centers.

Ethics Committee Approval: Ethics committee approval of our study was obtained from the Ethics Committee for Science, Social and NonInterventional Health Sciences Research at University of Health Sciences, Istanbul Yeni Yüzyıl University (approval number: 2019/2, date: 04.02.2019). 
12. Khairy P, lonescu-Ittu R, MacKie AS, Abrahamowicz M, Pilote L, Marelli AJ. Changing mortality in congenital heart disease. J Am Coll Cardiol 2010; 56: 1149-57.

13. Dorfman AT, Marino BS, Wernovsky G, Tabbutt S, Ravishankar C, Godinez $\mathrm{Rl}$, et al. Critical heart disease in the neonate: Presentation and outcome at a tertiary care center. Pediatr Crit Care Med 2008; 9: 193-202.

14. Lopes SAVDA, Guimarães ICB, Costa SFO, Acosta AX, Sandes KA, Mendes CMC. Mortality for critical congenital heart diseases and associated risk factors in newborns. A Cohort Study. Arq Bras Cardiol 2018; 111: 666-73.

15. Oster ME, Lee KA, Honein MA, Riehle-Colarusso T, Shin M, Correa A. Temporal trends in survival among infants with critical congenital heart defects. Pediatrics 2013; 131: e1502-8.

16. Peterson C, Ailes E, Riehle-Colarusso T, Oster ME, Olney RS, Cassell CH, et al. Late detection of critical congenital heart disease among US infants: estimation of the potential impact of proposed universal screening using pulse oximetry. JAMA Pediatr 2014; 168: 361-70.

17. Khoshnood B, Lelong N, Houyel L, Thieulin AC, Jouannic JM, Magnier $\mathrm{S}$, et al. Prevalence, timing of diagnosis and mortality of newborns with congenital heart defects: a population-based study. Heart 2012; 98: 166773.

18. Kalfa D, Krishnamurthy G, Duchon J, Najjar M, Levasseur S, Chai P, et al. Outcomes of cardiac surgery in patients weighing <2.5 kg: Affect of patient-dependent and -independent variables. J Thorac Cardiovasc Surg 2014; 148: 2499-506.

19. Polito A, Piga S, Cogo PE, Corchia C, Carnielli V, Da Frè M, et al. Increased morbidity and mortality in very preterm NLBW infants with congenital heart disease. Intensive Care Med 2013; 39: 1104-12.

20. Costello JM, Polito A, Brown DW, McElrath TF, Graham DA, Thiagarajan $\mathrm{RR}$, et al. Birth before 39 weeks' gestation is associated with worse outcomes in neonates with heart disease. Pediatrics 2010; 126: 277-84.

21. Costello JM, Pasquali SK, Jacobs JP, He X2, Hill KD2, Cooper DS, et al. Gestational age at birth and outcomes after neonatal cardiac surgery: An analysis of the society of thoracic surgeons congenital heart surgery database. Circulation 2014; 129: 2511-7.

22. Blue GM, Kirk EP, Sholler GF, Harvey RP, Winlaw DS. Congenital heart disease: current knowledge about causes and inheritance. Med J Aust 2012; 197: 155-9.

23. Mat Bah MN, Sapian MH, Jamil MT, Alias A, Zahari N. Survival and associated risk factors for mortality among infants with critical congenital heart disease in a developing country. Pediatr Cardiol 2018; 39: 1389-96.

24. Atz AM, Travison TG, Williams IA, Pearson GD, Laussen PC, Mahle WT, et al. Prenatal diagnosis and risk factors for preoperative death in neonates with single right ventricle and systemic outflow obstruction: screening data from the pediatric heart network single ventricle reconstruction trial(*). J Thorac Cardiovasc Surg 2010; 140: 1245-50.

25. Hoehn KS, Wernovsky G, Rychik J, Tian ZY, Donaghue D, Alderfer MA, et al. Parental decision-making in congenital heart disease. Cardiol Young 2004; 14: 309-14. 